\title{
ERRATUM
}

\section{Initial experience with a robotically operated video optical telescopic- microscope in cranial neurosurgery: feasibility, safety, and clinical applications}

TO THE READERSHIP: An error appeared in the article by Gonen et al. (Gonen L, Chakravarthi SS, Monroy-Sosa A, et al: Initial experience with a robotically operated video optical telescopic-microscope in cranial neurosurgery: feasibility, safety, and clinical applications. Neurosurg Focus 42:E9, 2017).

The Acknowledgments section was incomplete. The amended text is shown below.

We would like to thank Stryker Medical, Synaptive Medical, Nico Corporation, and Karl Storz Corporation for their support of the Aurora Neuroscience Institute Neuroanatomical Laboratory.

We are grateful to the Vince Lombardi Cancer Foundation for their support of our research.

The article has been corrected online as of February 1,2018 .

Amin B. Kassam, MD

Aurora Neuroscience Innovation Institute, Aurora St. Luke's Medical Center, Milwaukee, WI

INCLUDE WHEN CITING

DOI: 10.3171/2017.12.FOCUS1712a.

CAANS 2018, except where prohibited by US copyright law 